\title{
Effectiveness of Peer-Led Intervention on KAP Related to Sexual Reproductive and Mental Health Issues among Adolescents in Low Resource Settings India: A Comparative Study among Participants and Non-Participants in the Intervention
}

\author{
Kavya $\mathbf{P}^{{ }^{*} \text {, Sonali Daniel2 }}{ }^{2}$, Shumayla Shumayla ${ }^{3}$, Rajesh Sinha ${ }^{3}$, Sunil Mehra ${ }^{4}$ \\ ${ }^{1}$ Mental Health Department, Mamta-Health Institute for Mother and Child, Delhi, India \\ ${ }^{2}$ Chronic Diseases and Adolescent Health Department, Mamta-Health Institute for Mother and Child, Delhi, India \\ ${ }^{3}$ Research Department, Mamta-Health Institute for Mother and Child, Delhi, India \\ ${ }^{4}$ Mamta-Health Institute for Mother and Child, Delhi, India \\ Email: *kavyap@mamtahimc.org
}

How to cite this paper: P, K., Daniel, S., Shumayla, S., Sinha, R. and Mehra, S. (2020) Effectiveness of Peer-Led Intervention on KAP Related to Sexual Reproductive and Mental Health Issues among Adolescents in Low Resource Settings India: A Comparative Study among Participants and NonParticipants in the Intervention. Health, 12, 1151-1168.

https://doi.org/10.4236/health.2020.129085

Received: August 20, 2020

Accepted: September 15, 2020

Published: September 18, 2020

Copyright $\odot 2020$ by author(s) and Scientific Research Publishing Inc. This work is licensed under the Creative Commons Attribution International License (CC BY 4.0).

http://creativecommons.org/licenses/by/4.0/ (c) (i) Open Access

\section{Abstract}

Background: India being the country with largest adolescent population in the world, needs a special focus on the health services as the status of an adolescent determines the health status in his/her adulthood. Some of the major issues faced by the adolescents include: mental health problems, early pregnancy and childbirth, (HIV/STI) and other infectious diseases, violence, injuries and malnutrition. The present study aims to understand the effectiveness of peer-led intervention on knowledge, attitude and practices related to sexual reproductive and mental health issues in adolescents among participants and non-participants. The study was carried out to improve the health-seeking behaviour of adolescents on sexual reproductive and mental health issues in low resource setting across four states in India. Methods: The study adopted a cross-sectional survey which was conducted on 400 adolescents from each of the four districts namely Bangalore, Khagaria-Bihar, Khed-Pune and Sahinganj-Jharkhand. A comparative analysis was conducted between the participants and the non-participants of the intervention to understand the effectiveness of the intervention on the KAP related to sexual reproductive and mental health of adolescents. Results: The study shows that the participants from Karnataka and Maharashtra had better knowledge in emergency contraception, HIV awareness, use of contraceptives and consumption of IFA's than 
the non-participants; both the participants and the non-participants showed a positive behaviour in help-seeking in case of psychological challenges. Conclusion: The peer-led approach was found to be an effective strategy for learning, sharing and monitoring adolescent sexual reproductive and mental health.

\section{Keywords}

Adolescent Health, Mental Health, Peer-Led Approach, Sexual Reproductive Health

\section{Introduction}

Adolescence is a period of dynamic brain development and complex interaction with the social environment shaping the capabilities an individual takes forward into adult life [1]. India has the largest adolescent population in the world [1]. Despite representing a large sub-proportion i.e. $21 \%$ of the total population in the country, adolescents are widely excluded, largely invisible and unaddressed. The health status of an adolescent determines the health status in his/her adulthood [2]. The main health issues faced by the adolescents include mental health problems, early pregnancy and childbirth, human immunodeficiency virus/sexually transmitted infection (HIV/STI) and other infectious diseases, violence, unintentional injuries, malnutrition and substance abuse [3] [4] [5].

National data on adolescents (though limited) reveal a dismal picture about adolescent knowledge on sexual reproductive health, mental health and nutrition. Though adolescents in India have a high level of information about sexual and reproductive health (NFHS-4), however, there is a dearth of comprehensive knowledge among them [6] [7]. Adolescent girls are at risk of unwanted pregnancy, reproductive tract infections (RTIs) and also a spectrum of social and psychological consequences such as discontinuation of education, forced early marriages, unplanned pregnancies, unsafe abortions, and depression [8]. Practices adopted by sexually active adolescents can put them in a risk to sexual health. An earlier age of initiation of sexual activity has been associated with less frequent condom use, greater number of sexual partners, elevated rates of STDs and unplanned pregnancies [9]. About $0.10 \%$ of young people (15 - 24 years) are living with HIV (NFHS-4). Prevalence of mental disorders among adolescents aged 13 - 17 years is 7.3\% (National Mental Health Survey, 2015-16).

Studies suggest that the mental health literacy among adolescents was found to be very low; i.e. depression was identified by $29.04 \%$ and schizophrenia/psychosis was recognized only by $1.31 \%$. Stigma was noted to be present in help-seeking [10]. A study conducted in Afghanistan suggests that the community-based systems in low-income countries yielded positive results in creating awareness, thereby impacting participation [11]. 
The government of India has identified peer-led approach as an operative means for addressing health literacy and challenges among adolescents [12]. A systematic review conducted on the role of lay health workers in primary and secondary health care has shown positive results in the uptake of health services [13]. Peer-led approach being cost-effective [14] it is considered to be an effective health promotion strategy [15].

\section{Our Peer-Led Intervention Approach}

Project "Improving health-seeking behaviour on maternal and child health in low resource settings by incorporating reproductive mental health issues in current $\mathrm{RMNCH}+\mathrm{A}$ strategy in four districts of India” was implemented for three years from 2017-2020 in four districts of India viz. Bangalore (Urban)-Karnataka, Pune, Khed-Maharashtra, Khagaria-Bihar, Sahibgunj-Jharkhand. Figure 1 represents the intervention model of the project, which was designed to provide integrated service delivery package through using peer-led approach for adolescents to improve the KAP around reproductive sexual and mental health, there was an assumption that behaviour is socially influenced and that behavioural norms are developed through interaction. This approach was used in the project to promote behaviour change amongst young mothers and adolescents. It also developed a mechanism in the community to address continuity in information, counselling and health seeking behaviours.

Keeping in view the above mentioned challenges, to address the gaps in the implementation of Adolescent Health programme MAMTA with Support of Philip India CSR initiative implemented peer-led initiatives to improve the knowledge, attitude, practice and behaviour of adolescents, about sexual reproductive health, nutrition and common mental health issues using $\mathrm{RMNCH}+\mathrm{A}$

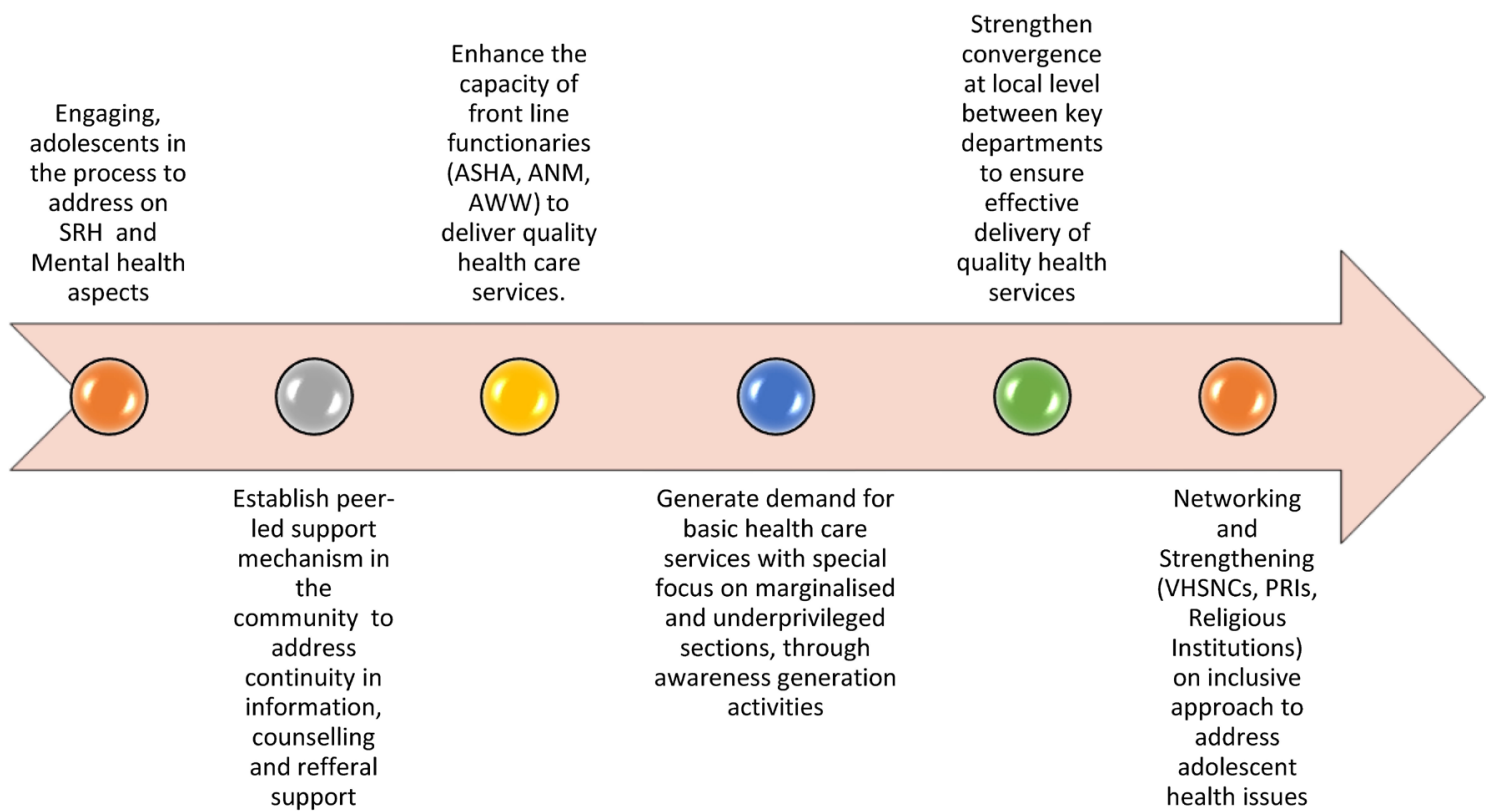

Figure 1. Intervention model: Schematic representation of the peer-led intervention model. 
service delivery platform. Hence the present study aims to assess the effectiveness of peer-led intervention on knowledge, attitude and practices related to sexual reproductive and mental health issues in adolescents among participants and non-participants.

\section{Methodology}

\subsection{Study Design}

A cross sectional comparative study was carried out to understand the effectiveness of peer-led intervention on Knowledge Attitude and Practices among participants and non-participants about sexual reproductive and mental health issues among adolescent boys and girls (10 - 19 years) from each of the four districts in the month of March 2020.

\subsection{Selection of Study Villages/Wards}

The villages/wards for data collection in all four districts were chosen by using Probability Proportional to Size (PPS) technique. PPS is a sampling procedure under which the probability of a unit being selected is proportional to the size of the ultimate unit, i.e. more massive clusters will have high probability. However, by sampling precisely the same number of individuals per Primary Sampling Unit (PSU), individuals in large PSU have smaller probability of being sampled. Due to this, overall, second stage compensates first stage so that each individual in the population has the same probability of being sampled.

\subsection{Sample Size Calculation}

For sample size calculation Cochranes formula was used [16].

i.e. $n=p q z^{2} / d^{2}$;

$n=$ required sample size;

$p=$ proportion of the population having the characteristic;

$q=1-p$;

$z=z$ value of confidence level;

$d=$ degree of precision.

The proportion of the population $(p)$ was taken as 0.5 as unknown prevalence, and it assumes maximum heterogeneity (i.e. a 50/50 split).

Further the confidence level was kept as $95 \%$ ( $z$ value of $95 \%$ confidence level is 1.96), degree of precision as $5 \%$ and accounting for sampling error of $5 \%$. So, by considering all these parameters, the sample size for the study was calculated as 400 for adolescents for each district

\subsection{Selection of Respondents}

The list of eligible adolescents in the age group of 10 - 19 years was collected from the Anganwadi Centres/Panchayat of the selected villages/wards, and final subjects were identified randomly using computer-generated random numbers based on project database their participation in intervention was deter- 
mined.

The study was carried out in four districts of India viz. Bangalore (Urban)Karnataka, Pune, Khed-Maharashtra, Khagaria-Bihar, Sahibgunj-Jharkhand. The study area consisted of rural villages and urban wards. A semi structured interview questionnaire was developed for data collection. The tool was translated in local languages namely Hindi (For Bihar and Jharkhand) Marathi (For Maharashtra) and Kannada (For Karnataka) and pilot tested for internal consistency and meaning conveyed by the questions. Changes and feedback after the pilot testing were incorporated and the questionarre was validated by collecting a sample of 25 participants. The study captured the change in knowledge, attitude and behaviour of adolescents (10 - 19 years) for health-seeking behaviour on sexual reproductive and common mental health issues. Informed consent and assent forms were developed and translated in local languages. Investigators explained the purpose of the study, its pros and cons, and participants write to refuse from participation. They were also informed that they can stop interview anytime during the process of interview and they will not have any adverse effects of doing that. During the process, no photographs were taken or audio recording was done.

\subsection{Data Collection}

The study used quantitative method for data collection. The team of field investigators were an equal representation of gender and were chosen from the nearby districts with proficiency in the local language. They were trained on ethical aspects, process of consent, assent and interview schedule in detail; they were also given practical experience for tablet based data entry using CAPI. The data was collected on the server which was password protected and with access permission only to data analysis team. Personal identifications such as name, phone number etc. were removed from the data sheet prior to the data analysis.

\subsection{Ethical Considerations}

Ethical approval was sought from MAMTA's institutional ethical review board prior to the study. The participants were informed about the objectives of the study with details of consent and assent before the data collection. Those individuals who willingly gave their written consent and assent for the participation were included in the study. The signed hard copies of consent and assent forms have been stored as per institutional ethical norms.

There was no incentive provided for participating in the study. Interview was conducted at a place and time convenient to the adolescents while maintaining complete privacy and confidentiality. Measures were taken to keep the language of the question simple and clear for the participant to have a better understanding. The responses given by adolescent were not shared with anyone including their family members. 


\subsection{Data Analysis}

The internal comparison groups for adolescents were created as participant group and non-participant group across the districts for conducting state-wise analyses. SPSS version 22.0 was used for analyses. These comparison groups were created to assess the difference in knowledge and practices of the participants who attended the group sessions versus those who did not attend the community interventions or the group sessions conducted by MAMTA. The respondents who participated in the community interventions and group interventions by MAMTA were considered as the participants and those who did not participate were considered non-participants.

\section{Results}

The knowledge and practices related to sexual and reproductive health were assessed through interview of the respondents between the age group of $10-19$ years of age. Also, their mental wellbeing was examined through the set of questions related to their social and emotional habits. For better comprehension, the results are divided into four areas:

- Socio-demographic profile of the adolescents;

- Awareness generation through sessions conducted by MAMTA;

- Knowledge of sexual and reproductive health issues;

- Mental health and wellbeing.

Even-though a sample of 400 in each district was to be collected, due to lockdown for COVID 19 the sample of 400 could not be reached, hence maximum sample collected for the state has been analyzed.

\subsection{Socio-Demographic Profile of the Adolescents}

Table 1 shows that among the overall adolescents interviewed, 49\% were boys and $51 \%$ were girls. $50.2 \%$ of adolescents were in 10 - 14 years' age group (early adolescents) whereas $49.8 \%$ were in 15 - 19 years' age group (late adolescents).

Table 2 shows the socio-demographic profile of 345, 308, 406 and 267 participants and non-participants in Bihar, Maharashtra, Jharkhand and Karnataka respectively. The majority of the respondents in Bihar belonged to Schedule caste (40\% and 43.6\%); Maharashtra had General (86.1\% and 66.7\%) in majority, OBC

Table 1. Age and sex wise distribution of adolescents interviewed in four states.

\begin{tabular}{cccccc}
\hline \multirow{2}{*}{ Name of State } & \multicolumn{2}{c}{ No. of Adolescents Interviewed } & \multicolumn{2}{c}{ Age group (Yrs.) } \\
\cline { 2 - 6 } & Boys & Girls & Total & $10-14$ & $15-19$ \\
\hline Bihar & 169 & 176 & 345 & 152 & 193 \\
Jharkhand & 204 & 202 & 406 & 159 & 247 \\
Maharashtra & 145 & 163 & 308 & 167 & 141 \\
Karnataka & 136 & 131 & 267 & 188 & 79 \\
Total & $654(49 \%)$ & $672(51 \%)$ & 1326 & $666(50.2 \%)$ & $660(49.8 \%)$ \\
\hline
\end{tabular}


Table 2. Demographic details of participants and non-participant adolescents across the four states

\begin{tabular}{|c|c|c|c|c|c|c|c|c|}
\hline \multirow{3}{*}{ Socio-Demographic Details } & \multicolumn{2}{|c|}{ Bihar $n=345$} & \multicolumn{2}{|c|}{ Jharkhand $n=406$} & \multicolumn{2}{|c|}{ Karnataka n = 267} & \multicolumn{2}{|c|}{ Maharashtra $n=308$} \\
\hline & $\mathbf{P}$ & NP & $\mathbf{P}$ & NP & $\mathbf{P}$ & NP & $\mathbf{P}$ & NP \\
\hline & $\mathrm{n}=180$ & $\mathrm{n}=165$ & $\mathrm{n}=315$ & $\mathrm{n}=91$ & $\mathrm{n}=186$ & $\mathrm{n}=81$ & $\mathrm{n}=287$ & $\mathrm{n}=21$ \\
\hline \multicolumn{9}{|l|}{ Social group } \\
\hline \multirow{2}{*}{ General Caste } & 34 & 18 & 22 & 5 & 10 & 6 & 247 & 14 \\
\hline & $18.9 \%$ & $10.9 \%$ & $7 \%$ & $5.5 \%$ & $5.4 \%$ & $7.4 \%$ & $86.1 \%$ & $66.7 \%$ \\
\hline \multirow{2}{*}{ Scheduled Caste } & 72 & 72 & 45 & 8 & 166 & 47 & 21 & 2 \\
\hline & $40 \%$ & $43.6 \%$ & $14.3 \%$ & $8.8 \%$ & $89.2 \%$ & $58.0 \%$ & $7.3 \%$ & $14.3 \%$ \\
\hline \multirow[b]{2}{*}{ Scheduled Tribe } & 8 & 9 & 11 & 10 & 6 & 4 & 8 & 3 \\
\hline & $4.4 \%$ & $5.5 \%$ & $3.50 \%$ & $11 \%$ & $3.2 \%$ & $4.9 \%$ & $2.8 \%$ & $14.3 \%$ \\
\hline \multirow{2}{*}{ Other Backward Class } & 66 & 66 & 237 & 68 & 4 & 24 & 11 & 2 \\
\hline & $36.7 \%$ & $40 \%$ & $75.2 \%$ & $74.7 \%$ & $2.2 \%$ & $29.6 \%$ & $3.8 \%$ & $9.5 \%$ \\
\hline \multicolumn{9}{|l|}{ Economic group } \\
\hline \multirow{2}{*}{ Below Poverty Line and Below } & 129 & 118 & 260 & 66 & 162 & 69 & 93 & 6 \\
\hline & $71.7 \%$ & $71.5 \%$ & $82.5 \%$ & $72.5 \%$ & $87.1 \%$ & $85.2 \%$ & $32.4 \%$ & $28.6 \%$ \\
\hline \multirow{2}{*}{ Above Poverty Line } & 51 & 29 & 8 & 3 & 4 & 0 & 191 & 15 \\
\hline & $28.3 \%$ & $17.6 \%$ & $2.5 \%$ & $3.3 \%$ & $2.2 \%$ & 0 & $66.6 \%$ & $71.4 \%$ \\
\hline \multirow[b]{2}{*}{ Antyodaya Anna Yojna } & 0 & 1 & 10 & 11 & 0 & 2 & 3 & 0 \\
\hline & 0 & 0 & $3.2 \%$ & $12.1 \%$ & 0 & $2.5 \%$ & $1 \%$ & 0 \\
\hline \multicolumn{9}{|l|}{ Religion } \\
\hline \multirow{2}{*}{ Hindu } & 178 & 163 & 252 & 67 & 158 & 49 & 271 & 17 \\
\hline & $98.9 \%$ & $98.8 \%$ & $80.0 \%$ & $73.6 \%$ & $84.9 \%$ & $60.5 \%$ & $94.4 \%$ & $81.0 \%$ \\
\hline \multirow{2}{*}{ Muslim } & 2 & 2 & 60 & 22 & 6 & 10 & 14 & 2 \\
\hline & $1.1 \%$ & $1.2 \%$ & $19.0 \%$ & $24.2 \%$ & $3.2 \%$ & $12.3 \%$ & $4.9 \%$ & $9.5 \%$ \\
\hline Christian & 0 & 0 & 0 & 0 & 22 & 22 & 0 & 0 \\
\hline Sikh & 0 & 0 & 3 & 2 & $11.8 \%$ & $27.2 \%$ & 0 & 0 \\
\hline \multirow[b]{2}{*}{ Others (Buddhism, Jainism) } & 0 & 0 & $1 \%$ & $2.2 \%$ & 0 & 0 & 2 & 2 \\
\hline & 0 & 0 & 0 & 0 & 0 & 0 & $0.7 \%$ & $9.5 \%$ \\
\hline \multicolumn{9}{|l|}{ Education } \\
\hline \multirow{2}{*}{ Primary } & 1 & 0 & 1 & 2 & 17 & 4 & 3 & 5 \\
\hline & $0.6 \%$ & $0.0 \%$ & $0.3 \%$ & $2.6 \%$ & $9.6 \%$ & $5.8 \%$ & $1.0 \%$ & $23.8 \%$ \\
\hline \multirow{2}{*}{ Upper Primary (5th-8th) } & 57 & 37 & 84 & 26 & 102 & 37 & 127 & 8 \\
\hline & $32.8 \%$ & $26.2 \%$ & $28.8 \%$ & $34.2 \%$ & $57.6 \%$ & $53.6 \%$ & $44.3 \%$ & $38.1 \%$ \\
\hline \multirow{2}{*}{ Secondary } & 62 & 54 & 73 & 15 & 40 & 20 & 76 & 4 \\
\hline & $35.6 \%$ & $38.3 \%$ & $25.0 \%$ & $19.7 \%$ & $22.6 \%$ & $29.0 \%$ & $26.5 \%$ & $19.0 \%$ \\
\hline \multirow{2}{*}{ Senior secondary } & 54 & 50 & 134 & 33 & 18 & 8 & 81 & 4 \\
\hline & $31 \%$ & $35.5 \%$ & $45.9 \%$ & $43.4 \%$ & $10.2 \%$ & $11.6 \%$ & $28.2 \%$ & $0 \%$ \\
\hline
\end{tabular}


(75.2\% and \& 74.2\%) were in majority in Jharkhand and Karnataka had Scheduled caste $(89.2 \%$ and $58 \%)$ in majority. Most of the respondents in Bihar, Jharkhand and Karnataka were below poverty line. The economic status was taken as APL or BPL based on the availability of type of ration card with the family. Hinduism was the prevalent religion in these states. The condition of education was better in Jharkhand, as $45.9 \%$ and $43.4 \%$ of the adolescent's had enrolled in senior secondary and above classes, while in Bihar (31\% and 35.5\%), Maharashtra (28.2\%) and Karnataka (10.2\% and 11.6\%) very few were pursuing senior secondary and above education.

\subsection{Satisfaction Levels about Awareness Generation Sessions}

Under the project community meetings and sessions were one of the strategic means used to address important sexual, reproductive and mental health issues among the adolescent boys and girls.

In Bihar, $88.9 \%$, Jharkhand $98.4 \%$ Maharashtra $72 \%$, Karnataka $72 \%$ of the respondents were benefited from the community meetings and sessions. Overall the satisfaction levels were more than $90 \%$ among the respondents who had participated in these meeting interventions.

\subsection{Knowledge and Awareness on SRH Issues}

To maintain one's sexual and reproductive health, adolescents need to have access to accurate information and safe, effective, affordable and acceptable contraception method of their choice. They must be informed and empowered to protect themselves from sexually transmitted infections and how to tackle the mental health issues.

\subsubsection{Knowledge about Why to Get Married at the Right Age}

Table 3 shows, in Bihar, among girls 34.4\% adolescents from the participant group while $8.5 \%$ of adolescents from the non-participants had knowledge on why a women should get married after 18 years of age. Amongst the boys, $36.1 \%$ of adolescents from the participant group and 53.3\% from the non-participant group were aware about why the boys should get married after 21 years of age. In Jharkhand, $70.5 \%$ of adolescent girls from the participant group and $12.1 \%$ of adolescent girls from the non-participant group had knowledge of why a women should get married after 18 years of age. $35.6 \%$ of the adolescent boys from the participant group and $22 \%$ of them from non-participant group were aware about the importance of getting married after 21 years of age. In Karnataka $8.6 \%$ of adolescent girls from the participant group and $14.8 \%$ from the non-participant group had knowledge on why girls should get married after 18 years of age. Amongst the boys, $34.9 \%$ of them from the participant group were aware about why boys should get married after 21 years of age as compared to $37 \%$ of them from the non-participant group. In Maharashtra $81.5 \%$ of adolescent girls from the participant group and $76.2 \%$ of the non-participants group had knowledge on why the women should get married after 18 years of age. Amongst the boys, $54.7 \%$ of 
Table 3. Knowledge, attitude and practices on Sexual reproductive health among participants and non-participant adolescents across the four states.

\begin{tabular}{|c|c|c|c|c|c|c|c|c|}
\hline \multirow[b]{2}{*}{ SRH Issues } & \multicolumn{2}{|c|}{ Bihar $n=345$} & \multicolumn{2}{|c|}{ Jharkhand $n=406$} & \multicolumn{2}{|c|}{ Karnataka $n=267$} & \multicolumn{2}{|c|}{ Maharastra $n=308$} \\
\hline & $\begin{array}{l}\text { Participants } \\
\mathrm{n}=180\end{array}$ & $\begin{array}{c}\text { Non } \\
\text { Participants } \\
\mathrm{n}=165\end{array}$ & $\begin{array}{c}\text { Participants } \\
\mathrm{n}=350\end{array}$ & $\begin{array}{c}\text { Non } \\
\text { Participants } \\
\mathrm{n}=91\end{array}$ & $\begin{array}{c}\text { Participants } \\
\mathrm{n}=186\end{array}$ & $\begin{array}{c}\text { Non } \\
\text { Participants } \\
\mathbf{n}=\mathbf{8 1}\end{array}$ & $\begin{array}{c}\text { Participants } \\
\mathrm{n}=287\end{array}$ & $\begin{array}{c}\text { Non } \\
\text { Participants } \\
n=21\end{array}$ \\
\hline \multicolumn{9}{|c|}{ Knowledge of why should one get married at the right age } \\
\hline \multirow{2}{*}{ Girls } & 62 & 14 & 222 & 11 & 16 & 12 & 234 & 16 \\
\hline & $34.4 \%$ & $8.5 \%$ & $70.5 \%$ & $12.1 \%$ & $8.6 \%$ & $14.8 \%$ & $81.5 \%$ & $76.2 \%$ \\
\hline \multirow{2}{*}{ Boys } & 65 & 88 & 112 & 20 & 65 & 30 & 157 & 16 \\
\hline & $36.1 \%$ & $53.3 \%$ & $35.6 \%$ & $22 \%$ & $34.9 \%$ & $37 \%$ & $54.7 \%$ & $76.2 \%$ \\
\hline \multicolumn{9}{|c|}{ Awareness on HIV/AIDS } \\
\hline \multirow{2}{*}{ Awareness on HIV } & 157 & 124 & 231 & 18 & 82 & 32 & 242 & 13 \\
\hline & $87.2 \%$ & $75.2 \%$ & $77.3 \%$ & $19.8 \%$ & $44.1 \%$ & $39.5 \%$ & $84.3 \%$ & $61.9 \%$ \\
\hline \multicolumn{9}{|c|}{ Knowledge on emergency contraception } \\
\hline Emergency & 77 & 76 & 144 & 14 & 46 & 6 & 70 & 9 \\
\hline Contraception & $42.8 \%$ & $46.1 \%$ & $45.7 \%$ & $15.4 \%$ & $24.7 \%$ & $7.4 \%$ & $24.4 \%$ & $42.9 \%$ \\
\hline \multicolumn{9}{|c|}{ Practices on contraceptive use } \\
\hline $\begin{array}{l}\text { Adolescents in physical } \\
\text { relationship }\end{array}$ & $\begin{array}{c}5 \\
2.8 \%\end{array}$ & $\begin{array}{c}6 \\
3.6 \%\end{array}$ & $\begin{array}{c}6 \\
1.9 \%\end{array}$ & $\begin{array}{c}16 \\
17.6 \%\end{array}$ & 0 & 0 & $\begin{array}{c}40 \\
13.9 \%\end{array}$ & $\begin{array}{c}4 \\
19 \%\end{array}$ \\
\hline $\begin{array}{l}\text { Use of contraceptives } \\
\text { during sex }\end{array}$ & $\begin{array}{c}2 \\
40 \%\end{array}$ & 0 & $\begin{array}{c}2 \\
33.3 \%\end{array}$ & $\begin{array}{c}3 \\
18.8 \%\end{array}$ & 0 & 0 & $\begin{array}{c}26 \\
65 \%\end{array}$ & $\begin{array}{c}2 \\
50 \%\end{array}$ \\
\hline \multicolumn{9}{|c|}{ Knowledge and practice on IFA consumption } \\
\hline $\begin{array}{l}\text { Knowledge about IFA } \\
\text { tablets among girls }\end{array}$ & $\begin{array}{c}101 \\
89.4 \%\end{array}$ & $\begin{array}{c}53 \\
84.1 \%\end{array}$ & $\begin{array}{c}123 \\
62.8 \%\end{array}$ & 0 & $\begin{array}{c}76 \\
66.7 \%\end{array}$ & $\begin{array}{c}9 \\
52.9 \%\end{array}$ & $\begin{array}{c}132 \\
84.6 \%\end{array}$ & $\begin{array}{c}3 \\
42.9 \%\end{array}$ \\
\hline Consumption of IFA & $\begin{array}{c}87 \\
544 \%\end{array}$ & $\begin{array}{c}67 \\
362 \%\end{array}$ & 119 & 4 & 60 & 25 & 130 & $\begin{array}{c}5 \\
140 \%\end{array}$ \\
\hline tablets & $54.4 \%$ & $36.2 \%$ & $41 \%$ & $3.4 \%$ & $44.8 \%$ & $18.8 \%$ & $47.6 \%$ & $14.3 \%$ \\
\hline
\end{tabular}

* "Yes" responses from each question are represented for analysis from the total sample of each district.

them from the participant group and $76.2 \%$ from the non-participants group were aware that why boys should get married after 21 years of age.

\subsubsection{Knowledge about HIV AIDS}

Table 3 shows, on the whole, the knowledge on safe sexual practices and HIV/AIDS and its transmission was better among participant group as compared to non-participant group. $87.2 \%$ of adolescents from participant group in Bihar had knowledge about HIV/AIDS, but the awareness was low in the nonparticipants group $75.2 \%$. In Jharkhand, $73.3 \%$ of adolescents from the participant group had knowledge about HIV/AIDS, but the awareness was low in the non-participant group, only $19.8 \%$ of adolescents from the non-participant group had heard of HIV/AIDS. In Karnataka $44.1 \%$ of adolescents had knowledge about HIV/AIDS from the participant group and 39.5\% of them from the non-participant group had heard of HIV/AIDS. In Maharashtra $84.3 \%$ of adolescents from participant group had knowledge about HIV/AIDS and $61.9 \%$ of adolescents from the non-participant group had heard of HIV/AIDS. 


\subsubsection{Knowledge on Emergency Contraception among Adolescents}

Table 3 shows, the state wise analysis of knowledge about emergency contraception among participant and non-participant group reveals that the participant group from Jharkhand $47.7 \%$ and Karnataka $24.7 \%$ had better awarenesss on emergency contraception than the non-participant group of Jharkhand $15.4 \%$ and Karnataka 7.4\%. On the contrary the non-participant groups from Bihar and Maharashtra were better aware $46.1 \%, 42.9 \%$ than the participant group $42.8 \%, 24.4 \%$ of both the states.

\subsubsection{Knowledge of Regular Methods of Contraception}

Table 3 shows, across all states, condom was the only or most commonly known contraceptive among non-participant group whereas awareness about methods oral pills, female sterilization, safe period IUD and male sterilization was more among the participant group across all the states.

Overall the knowledge on contraceptive methods was better in participant group as compared to non-participant group.

\subsubsection{Awareness and Practices on the Use of Contraceptive}

Table 3 shows that throughout the states, less number of adolescents from the participant group were sexually active as compared to non-participant group and the use of contraceptives was more in participant group among those who were sexually active.

In Bihar, $2.8 \%$ of adolescents from the participant group were in physical relationships, while $3.6 \%$ of adolescents from the non-participants were in physical relationships. $40 \%$ of adolescents from the participant group used contraceptives during intercourse, however the adolescents from the non-participant group did not prefer contraceptives due to lack of knowledge. As per the findings none of the adolescent from the non-participant group used contraceptive. In Jharkhand very few $1.9 \%$ from the participant group were in physical relationships whereas $17.6 \%$ from the non-participant group were in physical relations. 33.3\% from the participant group used contraceptives whereas none from the non-participant preferred contraceptives due to lack of knowledge. The findings show that only $18.8 \%$ from the non-participant group used any contraceptives. In Karnataka, none of the participant and non-participants were in physical relationships. In Maharashtra $13.9 \%$ from the participant group were in physical relationships and $19 \%$ from the non-participant were in physical relations. The adolescents from participant group who had physical relations used contraceptive $65 \%$ but the non-participant due to lack of knowledge did not prefer contraceptives. The findings suggest that only $50 \%$ of individuals from the non-participant group used contraceptive.

\subsubsection{Knowledge and Practice on Consumption of IFA (Weekly Iron Folic Acid Supplementation)}

Table 3 shows, in Bihar, $89.4 \%$ of adolescents from the participant group had knowledge about IFA tablets and took IFA tablets from school or Anganwadi. 
And amongst the non-participant group, the awareness level was low as compared to intervention as $84.1 \%$ of the respondents had heard of the tablet and its use. In Jharkhand, $62.8 \%$ from the participant group had knowledge about IFA tablets and took IFA tablets from school or Anganwadi. But amongst the non-participant group the awareness level was zero as none of them took IFA tablets or even had heard of the tablet and its use. In Karnataka, $66.7 \%$ from the participant group had knowledge about IFA tablets and took IFA tablets from school or Anganwadi. But amongst the non-participants 52.9\% were aware about taking IFA tablets. In Maharashtra, 84.6\% from the participant group had knowledge about IFA tablets and took IFA tablets from school or Anganwadi. But amongst the non-participant group the awareness level was $42.9 \%$. The consumption of IFA across the four states among the participant group was higher than the non-participant group.

\subsection{Mental Health Awareness and Wellbeing}

Adolescence is a crucial period for developing and maintaining social and emotional habits are important for mental well-being. These include adopting healthy sleep patterns; taking regular exercise; developing coping, problem-solving, and interpersonal skills; and learning to manage emotions. Supportive environments in the family, at school and in the wider community are also important. Therefore, the mental health and wellbeing status of adolescents was assessed across the four states. The questionnaire was designed to identify the presence of possible mental health issues experienced by adolescents in the one month preceding the interview.

\subsubsection{Violence amongst Adolescents}

Table 4 shows, in Bihar the verbal abuse was faced by participant group was $13.3 \%$ and among non-participants it was $38.1 \%$. The eve teasing was faced by adolescents from participant group was $4.4 \%$ and among non-participant it was 9.5\%, $6.3 \%$ of adolescents from the non-participants group $0.9 \%$ from the participant group faced sexual assault. In Jharkhand findings denote that there were various forms of violence faced by the adolescents but the individuals exposed to the same were very few in number. The verbal abuse was faced by participant group was $10.2 \%$ and non-participants group was $33.3 \%$. The eve teasing faced by adolescents was found to be negligible while the sexual abuse faced was 33\% among the non-participant group $2 \%$ among participant group. In Karnataka, verbal abuse was faced by respondents but very few in percentage participants $1.8 \%$; non-participants 0 . The sexual assault faced by adolescents was negligible, while eve teasing was faced by $12.3 \%$ of the participant group but no one amongst non-participant group. In Maharashtra, verbal abuse faced by participant group $30.8 \%$ and among non-participant it was $28.6 \%$. The eve teasing faced by adolescents in the non-participants group was found to be zero whereas from the participant group $17.3 \%$ faced eve teasing. From the non-participant group $28.6 \%$ and $16 \%$ from the participant group faced sexual assault. 
K. P et al.

Table 4. Mental health awareness and psychological wellbeing among participants and non-participant adolescents across the four states.

\begin{tabular}{|c|c|c|c|c|c|c|c|c|}
\hline \multirow[b]{2}{*}{ Mental Health issues } & \multicolumn{2}{|c|}{ Bihar $n=345$} & \multicolumn{2}{|c|}{ Jharkhand $n=406$} & \multicolumn{2}{|c|}{ Karnataka $n=267$} & \multicolumn{2}{|c|}{ Maharastra $n=308$} \\
\hline & $\begin{array}{l}\text { Participants } \\
\quad \mathrm{n}=180\end{array}$ & $\begin{array}{c}\text { Non } \\
\text { Participants } \\
\mathrm{n}=165\end{array}$ & $\begin{array}{c}\text { Participants } \\
\mathrm{n}=350\end{array}$ & $\begin{array}{c}\text { Non } \\
\text { Participants } \\
\mathrm{n}=91\end{array}$ & $\begin{array}{c}\text { Participants } \\
\mathrm{n}=186\end{array}$ & $\begin{array}{c}\text { Non } \\
\text { Participants } \\
\mathbf{n}=\mathbf{8 1}\end{array}$ & $\begin{array}{c}\text { Participants } \\
\text { n }=287\end{array}$ & $\begin{array}{c}\text { Non } \\
\text { Participants } \\
\mathrm{n}=21\end{array}$ \\
\hline \multicolumn{9}{|c|}{ Violence and Substance consumption } \\
\hline \multirow{2}{*}{ Verbal abuse } & 15 & 24 & 20 & 2 & 2 & \multirow{2}{*}{0} & 48 & 2 \\
\hline & $13.3 \%$ & $38.1 \%$ & $10.2 \%$ & $33.3 \%$ & $1.8 \%$ & & $30.8 \%$ & $28.6 \%$ \\
\hline \multirow{2}{*}{ Eve teasing } & 5 & 6 & 1 & \multirow{2}{*}{0} & 14 & \multirow{2}{*}{0} & 27 & \multirow{2}{*}{0} \\
\hline & $4.4 \%$ & $9.5 \%$ & $0.5 \%$ & & $12.3 \%$ & & $17.3 \%$ & \\
\hline \multirow{2}{*}{ Sexual assault } & 1 & 4 & 4 & 2 & \multirow{2}{*}{0} & \multirow{2}{*}{0} & 25 & 2 \\
\hline & $0.9 \%$ & $6.3 \%$ & $2 \%$ & $33.3 \%$ & & & $16 \%$ & $28.6 \%$ \\
\hline Consumption of tobacco & 11 & 24 & 17 & 8 & 16 & 8 & 34 & 0 \\
\hline and alcohol & $6.1 \%$ & $14.5 \%$ & $5.4 \%$ & $8.8 \%$ & $8.6 \%$ & $9.9 \%$ & $11.8 \%$ & 0 \\
\hline \multicolumn{9}{|l|}{ Psychological wellbeing } \\
\hline \multirow{2}{*}{ Less worry } & 47 & 35 & 45 & 14 & 56 & 30 & 136 & 13 \\
\hline & $26.1 \%$ & $21.2 \%$ & $14.3 \%$ & $15.4 \%$ & $30.1 \%$ & $37 \%$ & $47.4 \%$ & $61.9 \%$ \\
\hline \multirow{2}{*}{ Less restless } & 23 & 26 & 49 & 17 & 54 & 10 & 67 & 4 \\
\hline & $12.8 \%$ & $15.8 \%$ & $15.6 \%$ & $18.7 \%$ & $29 \%$ & $12.3 \%$ & $23.3 \%$ & $19 \%$ \\
\hline \multirow{2}{*}{ Feeling lonely } & 18 & 20 & 29 & 12 & 51 & 42 & 62 & 3 \\
\hline & $10 \%$ & $12.1 \%$ & $9.2 \%$ & $13.2 \%$ & $27.4 \%$ & $51.9 \%$ & $21.6 \%$ & $14.3 \%$ \\
\hline Emotional disturbance & 69 & 0 & 12 & 0 & 59 & 0 & 227 & 0 \\
\hline Emotional breakdown & 0 & 32 & 0 & 0 & 0 & 18 & 0 & 10 \\
\hline \multicolumn{9}{|l|}{ Help-Seeking } \\
\hline \multirow{2}{*}{ Asha } & 33 & 18 & \multirow{2}{*}{0} & \multirow{2}{*}{0} & 12 & 2 & 143 & 1 \\
\hline & $47.8 \%$ & $56.3 \%$ & & & $20.3 \%$ & $11.1 \%$ & $63 \%$ & $10 \%$ \\
\hline \multirow{2}{*}{ Psychologist/psychiatrist } & 10 & 4 & 1 & \multirow{2}{*}{0} & \multirow{2}{*}{0} & \multirow{2}{*}{0} & 73 & 7 \\
\hline & $14.5 \%$ & $12.5 \%$ & $8.3 \%$ & & & & $32.2 \%$ & $70 \%$ \\
\hline \multirow{2}{*}{ Family members } & 11 & 6 & 8 & \multirow{2}{*}{0} & 25 & 10 & 6 & 2 \\
\hline & $15.9 \%$ & $18.8 \%$ & $66.7 \%$ & & $42.4 \%$ & $55.6 \%$ & $2.6 \%$ & $20 \%$ \\
\hline Faith healers & 0 & 0 & $\begin{array}{c}2 \\
16.7 \%\end{array}$ & 0 & $\begin{array}{c}6 \\
10.2 \%\end{array}$ & 0 & 0 & 0 \\
\hline \multirow{2}{*}{ Close friends } & 15 & 4 & 1 & 0 & 16 & 6 & 5 & 0 \\
\hline & $21.7 \%$ & $12.5 \%$ & $8.3 \%$ & 0 & $27.1 \%$ & $33.3 \%$ & $2.2 \%$ & 0 \\
\hline
\end{tabular}

* "Yes" response from each question are represented for analysis from the total sample of each district.

\subsubsection{Tobacco and Alcohol Consumption}

Table 4 shows, the consumption of alcohol and tobacco was found to be more among the non-participant group than the participant group. $6.1 \%$ and $14.5 \%$ from Bihar, 5.4\% and 8.8\% from Jharkhand, 8.6\% and 9.9\% from Karnataka and $11.8 \%$ in Maharashtra from participants group consumed substances.

\subsubsection{Other Mental Health Issues and Support from Family Members \\ 1) Psychological wellbeing}

Table 4 shows, in Bihar the adolescents reported that they worried less com- 
pared to earlier (participants 26.1\%; non-participants 21.2\%) and felt less restless (participants 12.8\%; non-participants 15.8\%), 10\% from participant and $12.1 \%$ from non participant adolescents felt loneliness even with people around them. 69 adolescents from the participant group had faced the condition of emotional disturbance, while amongst the non-participant group, 32 adolescents have suffered from emotional breakdown. In Jharkhand the adolescents reported that they worried less compared to earlier (participants 14.3\%, non-participants $15.4 \%$ ) and felt less restless (participants 15.6\%, non-participants 18.7\%), 9.2\% from participant and $13.2 \%$ from non participant adolescents felt loneliness even with people around them. It has been reported that they had decisions making life skill and utilized it for their development; only 12 from the participant group seek help in the condition of emotional disturbance. In Karnataka the adolescents reported that they worried less for day to day things (participants $30.1 \%$; non-participants 37\%). They felt less restless (participants 29\%; non-participants $12.3 \%), 21.6 \%$ from participant and $51.9 \%$ from non participant adolescents felt loneliness even with people around them, 59 adolescents from the participant group faced the condition of emotional disturbance. Amongst the non-participant group only 18 faced emotional breakdown. In Maharashtra the adolescents reported that they worried less for day to day things (participant 47.4\%; nonparticipant $61.9 \%$ ). They even felt less restless (participant 23.3\%; non-participant 19\%), 227 adolescents from the participant group faced emotional disturbance. While amongst the non-participant group only 10 had emotional breakdown.

\section{2) Preference for seeking support on mental health issues}

Table 4 shows, in Bihar, majority of the adolescents from the participant group preferred ASHA (47.8\%) followed by family members (15.9\%) and Psychologist \& Psychiatrist (14.5\%). Among non-participants ASHA (56.3\%) was the most preferred person to seek help. Only $12.5 \%$ of the non-participants took help from psychologist and psychiatrist. In Jharkhand among the non-participants group only 2 sought help in case of emotional breakdown. The majority from the participant group preferred family (66\%) followed by faith healers $(16.7 \%)$ for help. Amongst non-participant group no one seeked help from anyone. In Karnataka the majority from the participant group preferred family $(42.4 \%)$ followed by close friends (27.1\%) for help. Among the non-participant group, family member (55.6\%) was the most preferred person to seek help followed by close friends (33.3\%). None of the participants and non-participants took help from psychologist and psychiatrist. In Maharashtra majority from the participant group preferred ASHA (63\%) followed by psychologist/psychiatrist (32.2\%) for help, while the non-participant group preferred psychologist/psychiatrist (70\%) to seek help.

\section{Discussion}

In the current study total 1316 adolescents were reached out. The comparison of 
knowledge, attitude and practice related among the intervention and non-intervention group reveals that overall in all four states the adolescents were benefitted with our intervention and had better knowledge attitude and practice related indicators on SRH and mental Health issues. Overall the satisfaction levels were more than $90 \%$ among the participants in all four states who attended the meetings.

Comparison of findings between participant and non-participant adolescents in the project activities in all four states showed positive improvements in knowledge about sexual and reproductive health e.g. contraceptives, knowledge about HIV/AIDS, how HIV is transmitted through unsafe sexual practice and others means for e.g. sharing of needle, infected blood transfusion, from HIV infected mother to baby, benefits of marriage after the legal age for boys and girls, use of contraceptive during sex, received IFA tablets from AWCs/schools, abuse faced and substance abuse. However, in Karnataka no significant difference was observed on knowledge about HIV/AIDS and menstrual hygiene management between participants and non-participants. Contrary to the expectation, knowledge regarding reasons for suitable age of marriage for boys and girls was found less among the participants compared to non-participants. Also, gender-based violence situation was found same between participants and non-participants. In Maharashtra, contrary to the expectation, knowledge regarding HIV transmitted through others means e.g. sharing of needle, infected blood transfusion, from HIV infected mother to baby was found less among the participants compared to non-participants. The adolescents from the participant group had better understanding on psychological wellbeing and were more open to seek help than the adolescents form the non participant group.

The present intervention also showed positive improvements in the knowledge level of adolescents on delaying age of marriage, family planning measures, knowledge about HIV/AIDS and its transmission, uptake of IFA supplements and mental wellbeing. Different projects have used community-based approaches to improve adolescent outcomes. In "Delaying Age of Marriage in rural Maharashtra" project, life skill education was given to adolescent girls (12 - 18 years of age), facilitated by a trained local woman in 17 villages resulting in delaying age of girls' marriage. A strong feature of this intervention was reaching out to out-of-school girls who are at a higher risk of early marriage [17]. Use of ICT, social media and multimedia has been successfully used for promotion of sexual and reproductive health (SRH) issues; in Rio de Janerio, Brazil, a radio based soap opera, sountrack with songs and a set of comic books were used for a successful "Entre Nos (Between Us) campaign developed and implemented by Promundo and a group of young men and women peer educators, Youth for Gender Equity (JPEG)". They used stories about young couples and their friends to tackle first sexual experience, condom use, unplanned pregnancy and adolescent parenthood, women's empowerment and gender equity. A similar approach was adopted in Uganda called Young Empowered and Healthy (YEAH). In both 
cases media was used to attract and encourage youth participation and a means to convey sexual health messages to a wider community. Life Skill Based Education (LSBE) curriculum in Pakistan was developed by an organisation Aauhung by working with and through communities, involving wide scale agreement and consultation with parents, communities, youth and teachers, which enabled young people in schools to access information and develop understanding on SRH without resistance on cultural and religious grounds [18].

Community based interventions have a higher potential of making normative changes in society in favour of women and adolescent girls. The impact is more likely to be sustainable. However, limitation with the community based integrated approach interventions has been the complexity of these interventions and difficulty in institutionalising them [19]. In most cases, it is difficult to delineate the factors that have been critical for making the change. There is a dearth of cost-effectiveness data in most of these studies [20].

MAMTA has been successful in reaching out to people. It has created greater impact in terms of high uptake of services amongst women and adolescents and also created a cadre of champions as outreach workers who can be torch bearers in the community to support in awareness generation activities and community mobilization for accessing services.

\section{Conclusion}

Group meetings and sessions in the community as a part of peer-led approach were also found to be good strategy which is being utilized for learning, sharing and monitoring adolescent reproductive and mental health. Comparison of findings between participant and non-participant adolescents in the project activities showed positive improvements in knowledge about sexual and reproductive health e.g. contraceptives, knowledge about HIV/AIDS, how HIV is transmitted through unsafe sexual practice and through others means e.g. sharing of needle, infected blood transfusion, from HIV infected mother to baby, benefits of marriage after the legal age for boys and girls, use of contraceptive during sex, received IFA tablets from AWCs/schools, abuse faced and substance abuse. Though lesser number of cases of sexual assault were found among those who participated in the project activities however, increase in cases of eve teasing and increase in substance abuse were observed more in two districts among those who participated in the project activities compared to those who did not. No significant changes were observed on menstrual hygiene management, mental wellbeing and sought help from ASHAs during any mental issue.

\section{Recommendations}

Introducing age appropriate sex education with abuse prevention skills at schools, colleges and also in the community to bridge the knowledge gap in adolescent is required. With this approach, sexual abuse, early sex debut and unsafe sexual practice can be reduced, and the contraceptives usage can be increased. 
This in turn prevents unwanted pregnancy, AIDS/STIs and related complications. More focus should be laid on generating knowledge on menstrual hygiene and management, RTI/STIs, HIV/AIDS, and its treatment related services as this area needs further strengthening. There is need to encourage community participation in mobilizing adolescents to build life skills and to take active part in community programs. Addoelscents need to feel sense of security and confidentiality while dealing with their mental health issues and teleconsultation and telecounselling can be considered. Addressing gender-based violence against adolescents (especially girls) is something that project needs to look deeply into as this is affecting their access to information and health services Therefore, the intervention must devise an inclusive and gender transformative strategy to implement quality project delivery focusing on all segments of the society.

\section{Limitations}

The targeted sample size was not achieved due to the COVID pandemic restrictions. Some of the variables such as knowledge on right age at marriage and emergency contraception were observed to be better among the non-participants in Bihar and Jharkhand than the participants, as the line listing was carried out for three years to meet the targeted number of beneficiaries and the new participants were not benefitted from the sessions that had taken place earlier, besides there were irregularities in attending the sessions due to migration to the districts for further studies and the time gap between administration of one module to another module.

\section{Funding Details}

This study for MAMTA Health Institute for Mother and Child was supported by CSR division of PHILIPS INDIA.

\section{Acknowledgements}

The authors are indebted to all the study participants for providing needed information and their time. Our sincere gratitude to all the staff members from the central and district teams for their constant support throughout the study.

\section{Conflicts of Interest}

The authors declare that they have no competing interests.

\section{References}

[1] Ramadass, S., Gupta, S.K. and Nongkynrih, B. (2017) Adolescent Health in Urban India. Journal of Family Medicine and Primary Care, 6, 468-476. https://doi.org/10.4103/2249-4863.222047

[2] Maliye, C. and Garg, B.S. (2017) Adolescent Health and Adolescent Health Programs in India. Journal of Mahatma Gandhi Institute of Medical Sciences, 22, 78-82. https://doi.org/10.4103/jmgims.jmgims_32_17

[3] Sivagurunathan, C., Umadevi, R., Rama, R. and Gopalakrishnan, S. (2015) Adoles- 
cent Health: Present Status and Its Related Programmes in India. Are We in the Right Direction? Journal of Clinical and Diagnostic Research, 9, LE01-LE06. https://doi.org/10.7860/JCDR/2015/11199.5649

[4] Sunitha, S. and Gururaj, G. (2014) Health Behaviours \& Problems among Young People in India: Cause for Concern \& Call for Action. The Indian Journal of Medical Research, 140, 185-208.

[5] Sarada Mamilla, S.G. (2019) Knowledge about Menstrual Hygiene, Sexual Health, and Contraception in Educated Late Adolescent Age Girls. Journal of Family Medicine and Primary Care, 8, 610-613. https://doi.org/10.4103/jfmpc.jfmpc_320_18

[6] Ahmed, M. and Kusuma, M.L. (2016) Knowledge and Attitude of Pre-University Adolescent Girls Regarding STDs/ HIV and Sexual Health in Mysore City. International Journal of Medical Science and Public Health, 5, 2452-2456. https://doi.org/10.5455/ijmsph.2016.22042016493

[7] Ismail, S., Shajahan, A., Sathyanarayana Rao, T.S. and Wylie, K. (2015) Adolescent Sex Education in India: Current Perspectives. Indian Journal of Psychiatry, 57, 333-337. https://doi.org/10.4103/0019-5545.171843

[8] Shankar, P., Dudeja, P., Gadekar, T. and Mukherji, S. (2017) Reproductive Health Awareness Among Adolescent Girls of a Government School in an Urban Slum of Pune City. Medical Journal of Dr. DY Patil University, 10, 133-137. https://doi.org/10.4103/0975-2870.202101

[9] Dutt, S. and Manjula, M. (2017) Sexual Knowledge, Attitude, Behaviors and Sources of Influences in Urban College Youth: A Study from India. Indian Journal of Social Psychiatry, 33, 319-326. https://doi.org/10.4103/0971-9962.218602

[10] Srivastava, K., Chatterjee, K. and Bhat, P.S. (2016) Mental Health Awareness: The Indian Scenario. Industrial Psychiatry Journal, 25, 131-134. https://doi.org/10.4103/ipj.ipj_45_17

[11] Trani, J.F., Ballard, E., Bakhshi, P. and Hovmand, P. (2016) Community Based System Dynamic as an Approach for Understanding and Acting on Messy Problems: A Case Study for Global Mental Health Intervention in Afghanistan. Conflict and Health, 10, Article No. 25. https://doi.org/10.1186/s13031-016-0089-2

[12] Government of India. Rashtriya Kishor Swasthya Karyakram.

[13] Lewin, S., Munabi-Babigumira, S., Glenton, C., Daniels, K., Bosch-Capblanch, X., Van Wyk, B.E., et al. (2010) Lay Health Workers in Primary and Community Health Care for Maternal and Child Health and the Management of Infectious Diseases. Cochrane Database of Systematic Reviews, No. 3. Article No. CD004015. https://doi.org/10.1002/14651858.CD004015.pub3

[14] Boyle, J., Mattern, C.O., Lassiter, J.W. and Ritzler, J.A. (2011) Peer 2 Peer: Efficacy of a Course-Based Peer Education Intervention to Increase Physical Activity Among College Students. Journal of American College Health, 59, 519-529. https://doi.org/10.1080/07448481.2010.523854

[15] Shankar, P., Sievers, D. and Sharma, R. (2020) Evaluating the Impact of a SchoolBased Youth-Led Health Education Program for Adolescent Females in Mumbai, India. Annals of Global Health, 86, Article 57. https://doi.org/10.5334/aogh.2791

[16] Cochran, W.G. (1977) Sampling Techniques. 3rd Edition, John Wiley \& Sons, New York.

[17] Pande, R., Kurz, K., Walia, S., Macquarrie, K. and Jain, S. (2006) Improving the Reproductive Health of Married and Unmarried Youth in India: Delaying Age at Marriage in Rural Maharashtra, India. International Center for Research on Women 
(ICRW), Washington DC.

[18] Dunne, M., Durrani, N., Crossouard, B. and Fincham, K. (2014) Youth as Active Citizens Report: Youth Working towards Their Rights to Education and Sexual Reproductive Health.

[19] Lee-Rife, S., Malhotra, A., Warner, A. and Glinski, A.M. (2012) What Works to Prevent Child Marriage: A Review of the Evidence. Studies in Family Planning, 43, 287-303. https://doi.org/10.1111/j.1728-4465.2012.00327.x

[20] Chatterjee, K.E.Y.A. (2015) What Could Work to Prevent Child Marriages and Delay Pregnancy during Adolescence in India: A Systematic Review of Evidences from Low and Middle Income Countries. European Academic Research, 3, 1458-1490. 